\title{
IS A CALORIE REALLY A CALORIE? METABOLIC ADVANTAGE OF LOW-CARBOHYDRATE DIETS
}

Anssi H. Manninen, Advanced Research Press, Inc., Setauket, New York, USA. Address correspondence to sportsnutrition@luukku.com

Received July 24, 2004/Accepted November 15, 2004/Published (online)

\begin{abstract}
The first law of thermodynamics dictates that body mass remains constant when caloric intake equals caloric expenditure. It should be noted, however, that different diets lead to different biochemical pathways that are not equivalent when correctly compared through the laws of thermodynamics. It is inappropriate to assume that the only thing that counts in terms of food consumption and energy balance is the intake of dietary calories and weight storage. Wellcontrolled studies suggest that calorie content may not be as predictive of fat loss as is reduced carbohydrate consumption. Biologically speaking, a calorie is certainly not a calorie. The ideal weight loss diet, if it even exists, remains to be determined, but a high-carbohydrate/low-protein diet may be unsatisfactory for many obese individuals. Journal of the International Society of Sports Nutrition. 1(2):21-26, 2004
\end{abstract}

Keywords: low-carbohydrate diets, ketogenic diets, high-protein diets, obesity, energy balance, Atkins diet, body composition, thermodynamics

\section{INTRODUCTION}

Obesity results from an excess of energy intake over energy expenditure. If the obese individual wants to lose weight, then the solution is extremely simple: energy expenditure must exceed energy intake for a suitable length of time. Obviously, this message is simple in principle, but very difficult to put into practice. Indeed, more than half of the adult population must now be classified as overweight or obese in the USA. It has been suggested that low-fat diets promote fat loss, but Willett and Leibel concluded that fat consumption within the range of 18 to 40 percent energy appears to have little if any effect on body fatness ${ }^{1}$. Thus, they felt that diets high in fat do not appear to be the primary cause of obesity, and reductions in fat will not be the solution. Similarly, the recent Cochrane review concluded that fat-restricted diets are no better than calorie restricted diets in achieving long-term weight loss in overweight or obese people $^{2}$. In fact, participants lost slightly more weight on the control diets.

Thus, in reality were low-fat weight loss diets to be marketed according to the laws governing the pharmaceutical industry, they would not pass scrutiny, as they have not been shown to be more effective than control diets. Consequently, progressive scientists and health care professionals are beginning to question the wisdom of recommending the low-fat diets for weight loss. For example, Weinberg suggested that low-fat/highcarbohydrate diets may well have played an unintended role in the current epidemics of obesity, lipid abnormalities, type II diabetes and metabolic syndromes ${ }^{3}$. The popularity of the low-carbohydrate weight loss diets is unquestionable. This review examines the science behind the "metabolic advantage" (i.e., a greater weight loss/fat loss compared to isocaloric high-carbohydrate diet) of lowcarbohydrate diets. 


\section{THERMODYNAMICS AND WEIGHT LOSS DIETS}

According to Albert Einstein, "Classical thermodynamics...is the only physical theory of universal content concerning which I am convinced that, within the framework of applicability of its basic concepts, will never be overthrown ${ }^{4}$." Indeed, the first law of thermodynamics describes one of the most important principles related to body weight. The basic tenet states that energy cannot be created or destroyed, but can be transformed from one form to another. The first law of thermodynamics can be written as follows:

$\Delta \mathrm{E}=\mathrm{q}-\mathrm{W}$

where $\Delta \mathrm{E}$ is the change in energy stores during any process, $\mathrm{q}$ is the heat produced during the process, and $\mathrm{w}$ is the work. The energy balance equation dictates that the energy potential of body mass remains constant when caloric intake equals caloric expenditure ${ }^{5}$. Simply stated,

Change in energy stores = energy intake energy expenditure

As discussed by Feinman and co-workers ${ }^{6-8}$, although this principle always applies, the application of this law within living organisms is not simple. Strictly speaking, as written, the above mentioned equation only applies to closed systems that are close to equilibrium and that do not carry out chemical reactions ${ }^{5}$. If matter can be exchanged between system and surroundings, then the system is an open one. In fact, all living organisms are open systems ${ }^{4}$. Life forms take in food from the environment and use it to maintain body temperature and to run the biochemical pathways of its body.

Obviously, living organisms are also far from equilibrium. The second law of thermodynamics also must be considered. The second law tells us that processes always go in the direction of randomness, or disorder (entropy). Whenever energy is exchanged, the efficiency will be imperfect and some energy will escape - usually in the form of heat - thus increasing entropy in the universe 9 . Importantly, the metabolic pathways that macronutrients follow may be very different due to the differences in hormonal state and enzymatic activity ${ }^{6,7}$.

\section{WHY LOW-CARBOHYDRATE DIETS PROMOTE WEIGHT LOSS}

The hormonal changes associated with a lowcarbohydrate diet include a reduction in the circulating levels of insulin along with increased levels of glucagons, leading to activation of phosphoenolpyruvate carboxykinase, fructose 1,6-biphosphatase, and glucose 6-phosphatase and inhibition of pyruvate kinase, 6-phosphofructo-1-kinase, and hexokinase, favoring gluconeogenesis over glycolysis. Gluconeogenesis is an energy-consuming process as 6 mol of ATP are consumed for the synthesis of $1 \mathrm{~mol}$ of glucose from pyruvate or lactate ${ }^{10}$. The transformation of gluconeogenic amino acids into glucose requires even more energy because ATP is needed to dispose of the nitrogen as urea ${ }^{10}$. Further, a lowcarbohydrate diet increases turnover of body proteins; and the energy-dependent processes of maintaining the turnover of proteins (Table 1 ), including synthesis, folding, targeting, regulatory processes, and protein breakdown have an overall cost to body energy homeostasis that is significantly higher than previously appreciated ${ }^{11}$.

Table 1. Some energy dependent processes associated with protein metabolism

\begin{tabular}{|c|c|}
\hline Processes & Description \\
\hline Protein Turnover & $\begin{array}{l}\text { Formation of initiation complexes*; } \\
\text { peptide bond synthesis }\end{array}$ \\
\hline RNA Turnover & $\begin{array}{l}\text { Ribosomal RNA; transfer RNA; pre- } \\
\text { messenger RNA splicing; and messenger } \\
\text { RNA }\end{array}$ \\
\hline Regulatory & Reversible phosphorylation, GTP-GDP \\
\hline Processes & $\begin{array}{l}\text { exchange proteins, ion pumps and } \\
\text { channels, second messengers }\end{array}$ \\
\hline $\begin{array}{l}\text { Nitrogen } \\
\quad \text { Metabolism }\end{array}$ & $\begin{array}{l}\text { Glutamine/glutamate cycle; glucose/ } \\
\text { alanine cycle; urea synthesis }\end{array}$ \\
\hline
\end{tabular}


Also, a low-carbohydrate diet is often high in protein. A recent study demonstrated that postprandial thermogenesis was increased $100 \%$ on a high-protein/low-fat diet $v s$. a high-carbohydrate/low-fat diet in healthy subjects ${ }^{12}$. Finally, ketogenic diets are characterized by elevations of free fatty acids, leading to the increased transcription of mitochondrial uncoupling proteins and of peroxisomal $\beta$-oxidation ${ }^{13}$. Uncoupling proteins allow the proton gradient generated by the respiratory chain to re-enter the mitochondria by pathways which bypass the F1 ATPase, resulting in the generation of heat rather than ATP. Also, fatty acids undergoing $\beta$-oxidation with peroxisomes have no mechanism for energy conservation and result solely in heat production ${ }^{13}$. The important bottom line is that this leads to metabolic inefficiency.

\section{CRITICAL REVIEW OF MAJOR LOW- CARBOHYDRATE PAPERS}

A recent paper intended as a systematic review concluded, "weight loss while using low-carbohydrate diets was principally associated with decreased caloric intake and increased diet duration, not with reduced carbohydrate content ${ }^{14}$." As pointed out by Kauffman ${ }^{15}$ however, in the true lowcarbohydrate group in the study, the mean weight loss in trials was $17 \mathrm{~kg}$, while in the higher-carbohydrate group it was only $2 \mathrm{~kg}$. Oddly enough, the authors did not consider this significant. As Kauffman pointed out, "the conclusions should have been that lowcarbohydrate diets are both safe and effective 15 ." Only by intermingling trials of low to medium and high-carbohydrate diets could the authors reach the misleading conclusion quoted above ${ }^{15}$. A recent report by Foster et al. concluded that a low-carbohydrate diet produced a greater weight loss than did the conventional diet for the first six months, although the differences were not significant at one year ${ }^{16}$. Samaha et al. randomly assigned 132 severely obese subjects to a lowcarbohydrate or calorie and fat-restricted (low-fat) diet ${ }^{17}$. Seventy-nine subjects completed this six-month study. It should be noted that the difference in consumption of energy from carbohydrate was quite narrow: $51 \%$ in the low-fat group and $37 \%$ in the lowcarbohydrate group. Total energy intake at the 6-month mark was $1567 \mathrm{kcal} /$ day in the low-fat group and $1630 \mathrm{kcal} /$ day in the lowcarbohydrate group. Thus, the lowcarbohydrate group consumed 54 extra kcal/day. Nevertheless, the low-carbohydrate group lost $5.8 \mathrm{~kg}$ (and was still losing weight at 6 months) vs. $1.9 \mathrm{~kg}$ (leveled off) in the low-fat group. Both groups were given an exceptional number of contacts with "experts in nutritional consulting", so the possible placebo and nocebo effects would be even more intense here ${ }^{18}$. Greene et al. found that people eating an extra $300 \mathrm{kcal}$ a day on a very-low-carbohydrate diet lost a similar amount of weight during a 12-week study as those on a low-fat diet ${ }^{19}$. Over the course of the study, subjects consumed an extra 25,000 kcal that should have added up to about a 7 pounds weight gain; it did not. The study was unique because all the food was prepared at an upscale Italian restaurant, so the researchers knew exactly what they ate, and one could not argue that diets were not palatable. Finally, a recent randomised, balanced, two diet study compared effects of isocaloric, energy-restricted ketogenic and low-fat diets on weight loss and body composition in overweight/obese men $(n=15)$ and women $(n=13)^{20}$. Despite significantly greater calorie intake (1855 vs. 1562 $\mathrm{kcal} /$ day), both between and within group comparison revealed a distinct advantage of a ketogenic diet over a low-fat diet for weight loss/fat loss for men. In fact, 5 men showed more than 10 pounds difference in weight loss. Majority of women also responded more favourable to the ketogenic diet, especially in terms of trunk fat loss.

Furthermore, the individual responses revealed that three men and four women who did the ketogenic diet first, regained body mass and fat mass after the switch to the lowfat, whereas no subjects regained weight or fat mass after switching to the ketogenic diet. 


\section{THE COMPOSITION OF WEIGHT LOSS}

Although the greater weight loss has obvious significance, an equally important question is related to the composition of weight loss. In 1965, Benoit et al. published the first systematic study of the effect of a very-lowcarbohydrate (ketogenic) diet on composition of weight loss ${ }^{21}$. They observed that when a 1,000-kcal ketogenic diet (10 g of carbohydrates/day) was fed for 10 days, their seven male subjects lost an average of 600 $\mathrm{g} /$ day, of which $97 \%$ was fat. Young et al. compared 3 isoenergetic $(1,800 \mathrm{kcal} /$ day $)$ and isoprotein ( $115 \mathrm{~g} /$ day) diets differing in carbohydrate content (30, 60, and $104 \mathrm{~g} /$ day)

22. After 9 weeks on the 30-g, 60-g, and 104$\mathrm{g}$ carbohydrate diets, weight loss was 16.2, 12.8 , and 11.9 kilograms and fat accounted for $95 \%, 84 \%$, and $75 \%$ of the weight loss, respectively. More recently, Volek et al. examined the effects of 6-week very-lowcarbohydrate diet on total and regional body composition $^{23}$. Interestingly, their results indicated that fat mass was significantly decreased $(-3.4 \mathrm{~kg})$ and lean body mass significantly increased $(+1.1 \mathrm{~kg})$ at week 6 .

As expected, a very-low-carbohydrate diet led to significant decrease in serum insulin concentrations and there was a significant correlation between the decrease in insulin and the decrease in body fat, indicating that adipose tissue mobilization was up-regulated, which was also supported by the elevated beta-hydroxybutyrate concentrations. Finally, Willy et al. examined the efficacy and metabolic impact of a ketogenic diet in the treatment of morbidly obese adolescents ${ }^{24}$. The authors concluded that ketogenic diet is "a safe and effective weight loss regimen... The weight loss with this approach is rapid, consistent, and almost exclusively from body fat stores." It is frequently claimed that additional weight loss with low-carbohydrate diets is entirely explained by dehydration. However, the classic study by Rabast et al. demonstrated that alterations in the water and electrolyte balance observed during the lowcarbohydrate diets are reversible phenomena and should thus not be regarded as causal agents of the different weight reduction ${ }^{25}$. Also, the modern studies that measured body composition by dual-energy X-ray absorptiometry did not find any indication of excessive reduction in lean body mass ${ }^{26,27}$. Thus, the greater weight loss is attributable to fat loss.

\section{HYPERINSULINEMIA AND BODY WEIGHT}

There is evidence that hyperinsulinemia increases fat mass without a concomitant increase in energy intake. For example, six adult patients with diabetes were studied by Carlson and Cambell on conventional insulin therapy and after 2 months of intensive insulin therapy while maintaining constant caloric intake and were compared with a group of 6 matched non-diabetic volunteers 28 . Not surprisingly, the results indicated that two months of intensive insulin therapy improved glycemic control dramatically. However, this improvement was achieved at a cost of a weight gain of about 2.6 kilograms over the 2 months treatment as the result of an increase in fat mass and not lean body tissue. Of the weight gain, $70 \%$ could be accounted for by elimination of glycosuria and $30 \%$ by reduction in daily energy expenditure.

Although elimination of glycosuria is not relevant to healthy non-diabetic individuals, daily energy expenditure decreased 5\% (approximately $120 \mathrm{kcal} /$ day). The authors concluded that the reduction in the energy expenditure was the result of the decrease in triglyceride/free fatty acid cycling and nonoxidative glucose and protein metabolism. The triglyceride/free fatty acid (TG/FFA) cycling represents those FFAs that are hydrolysed from TG stores and are subsequently re-esterified back to TG rather than being oxidized. Non-oxidative glucose metabolism refers to glycogen synthesis, Cori cycling, and urinary glucose loss. Nonoxidative protein metabolism represents protein synthesis and the amino acid contribution to gluconeogensis. 
Furthermore, there is growing body of evidence indicating that low-glycemic diets also influence body weight and resting energy expenditure independently of caloric intake. For example, in a cross over study, Augus et al. compared high-glycemic energy-restricted diet with an isocaloric low-glycemic diet in moderately overweight young men and reported that resting energy expenditure declined by $10.5 \%$ on the high-glycemic diet compared with $4.6 \%$ on the low-glycemic diet ${ }^{29}$. It is of some interest that the alfaglucosidase inhibitors, a class of oral hypoglycaemic agents that slow digestion of starch in the gastrointestinal tract, not only improve measures of glycemic control, but also produce modest weight loss ${ }^{30}$.

\section{CONCLUSION}

It is increasingly clear that the idea that "a calorie is a calorie" is misleading. The calorie content may not be as predictive of fat loss as is reduced carbohydrate consumption. Different diets (e.g., high-protein/lowcarbohydrate $v s$. low-protein/highcarbohydrate) lead to different biochemical pathways (due to the hormonal and enzymatic changes) that are not equivalent when correctly compared through the laws of thermodynamics ${ }^{6}$. Unless one measures heat and the biomolecules synthesized using ATP, it is inappropriate to assume that the only thing that counts in terms of food consumption and energy balance is the intake of dietary calories and weight storage. Recently, Feinman and Fine concluded: "Metabolic advantage with low carbohydrate diets is well established in the literature... Attacking the obesity epidemic will involve giving up many old ideas that have not been productive. "A calorie is a calorie" might be a good place to start ${ }^{31}$." However, there will be metabolic accommodations and one cannot assume that the metabolic advantage (i.e., greater weight loss compared to isocaloric high-carbohydrate diet) will stay the same over a long term. The ideal weight loss diet, if it even exists, remains to be determined, but a high-carbohydrate/low-protein diet may be unsatisfactory for many obese individuals.

\section{ACKNOWLEDGMENT}

I thank Prof. Richard Feinman (Department of Biochemistry, SUNY Downstate Medical Center, Brooklyn, NY) for helpful advice.

\section{REFERENCES}

1. Willett WC, Leibel RL. Dietary fat is not major determinant of body fat. Am J Med 2002;113:47S-59S.

2. Pirozzo S, Summerbell C, Cameron C, Glasziou P. Advice on low-fat diets for obesity. Cochrane Database Systematic Reviews 2002;(2):CD003640.

3. Weinberg SL. The diet-heart hypothesis: a critique. J Am Coll Cardiol 2004;43:731-733.

4. Haynie DT. Biological Thermodynamics. Cambridge, UK: Cambridge University Press, 2001.

5. McArdle WD, Katch FI, Katch VL. Exercise Physiology: Energy, Nutrition and Human Performance. Philadelphia, Pennsylvania: Lippincott Williams Wilkins, 2001.

6. Feinman RD, Fine EJ. Thermodynamics and metabolic advantage of weight loss diets. Metab Synd Relat Disord 2003; 1:209-219.

7. Feinman RD, Makowske M. Metabolic syndrome and low-carbohydrate ketogenic diets in the medical school biochemistry curriculum. Metab Synd Relat Disord 2003;1:189-197

8. Fein EJ, Feinman RD. Thermodynamics of weight loss diets. Nutr Metab (Lond) 2004 (in press).

9. Brooks GA, Fahey TD, White TP, Baldwin KM. Exercise Physiology: Human Bioenergetics and Its Applications. New York: McGraw-Hill, 2000.

10. Hue L. Regulation of gluconeogenesis in liver: In Handbook of Physiology - Section 7: The Endocrine System - Volume II: The Endocrine Pancreas and Regulation of Metabolism. Oxford: Oxford University Press, pp. 649-657, 2001.

11. Bier DM. The energy cost of protein metabolism: Lean and mean on Uncle Sam's team. In: The Role of Protein and Amino Acids in Sustaining and Enhancing Performance. Committee on Military Nutrition Research, Food and Nutrition Board, Institute of Medicine. Washington, D.C.: National Academies Press, pp. 109-119, 1999.

12. Johnston CS, Day CS, Swan PD. Postprandial thermogenesis is increased $100 \%$ on a high-protein, low-fat diet versus a highcarbohydrate, low-fat diet in healthy, young women. J Am Coll Nutr 2002;21:55-61.

13. Veech RL. The therapeutic implications of ketone bodies: the effects of ketone bodies in pathological conditions: ketosis, ketogenic diet, redox states, insulin resistance, and mitochondrial metabolism. Prostaglandins Leukot Essent Fatty Acids 2004;70:309-19.

14. Bravata DM, Sanders L, Huang J. Efficacy and safety of low-carbohydrate diets: a systematic review. JAMA 2003;289:1837- 
1850.

15. Kauffman JM. Bias in recent papers on diet and drugs in peer-reviewed medical journals. J Am Phys Surg 2004;9:11-14.

16. Foster GD, Wyatt HR, Hill JO, et al. A randomized trial of a low-carbohydrate diet for obesity. N Engl J Med 2003;348: 2082-90.

17. Samaha FF, Iqbal N, Seshadri P et al. A low-carbohydrate as compared with a low-fat diet in severe obesity. N Engl J Med 2003;348:2074-2081.

18. Kauffman JM. Low-carbohydrate diets. J Sci Exploration 2004;18:83-134.

19. Greene $\mathrm{P}$, Willett $\mathrm{W}$ et al. Pilot 12-week feeding weight loss comparison: low-fat vs. low-carbohydrate (ketogenic) diets [abstract]. Obes Res 2003;11:A23.

20. Volek JS, Sharman MJ, Cómez AL et al. Comparison of energy-restricted very-low-carbohydrate and low-fat diets on weight loss and body composition in overweight men and women. Nutr Metab (Lond) 2004 (in press).

21. Benoit FL, Martin RL, Watten RH. Changes in body composition during weight reduction in obesity. Balance studies comparing effects of fasting and a ketogenic diet. Ann Intern Med 1965;63:604-612.

22. Young CM, Scanlan SS Im HS et al. Effect on body composition and other parameters in obese young men of carbohydrate level of reduction diet. Am J Clin Nutr 1971;24:290-296.

23. Volek JS, Sharman MJ, Love DM et al. Body composition and hormonal responses to a carbohydrate-restricted diet. Metabolism 2002;51:864-870

24. Willi SM, Oexmann MJ, Wright NM et al. The effects of a high-protein, low-fat, ketogenic diet on adolescents with morbid obesity: body composition, blood chemistries, and sleep abnormalities. Pediatrics 1998;101:61-7

25. Rabast U, Vornberger KH, Ehl M. Loss of weight, sodium and water in obese persons consuming a high- or low-carbohydrate diet. Ann Nutr Metab 1981;25:341-349.

26 Brehm BJ, Seeley RJ, Daniels SR, D'Alessio DA. A randomised trial comparing a very low carbohydrate diet and a calorierestricted low fat diet on body weight and cardiovascular risk in healthy women. J Clin Endocrinol Metab 2003;88:1617-1623.

27. Willi SM, Oexmann MJ, Wright NM et al. The effects of a high-protein, low-fat, ketogenic diet on adolescents with morbid obesity: body composition, blood chemistries, and sleep abnormalities. Pediatrics 1998;101:61-67.

28. Carlson MG, Campbell PJ. Intensive insulin therapy and weight gain in IDDM. Diabetes 1993;42:1700-1707.

29. Agus MS, Swain JF, Larson CL et al. Dietary composition and physiological adaptation to energy restriction. Am J Clin Nutr 2000;71:901-907.

30. Hauner H. The impact pf pharmacotherapy on weight management in type 2 diabetes. Int J Obes Relat Metab Disord 1999;23:S12-S17.

31. Feinman RD, Fein EJ. "A calorie is a calorie" violates the second law of thermodynamics. Nutr $J$ 2004;3:9. 